Revista de Sociología 30(2020):13-36

DOI: https://doi.org/10.15381/rsoc.v0i30.18904

ISSN impreso: 1605-8933 / ISSN en línea: 1609-7580

\title{
Los intelectualesy la nación peruana. Reflexión en vísperas del Bicentenario
}

Sección ESTUDI0S

RECIBIDO: 03/05/2020

APROBADO: 30/05/2020

PUBLICADO ONLINE: 23/10/2020

\author{
Osmar Gonzales Alvarado \\ Universidad Ricardo Palma, Perú \\ osmar.sonzales@gmail.com \\ https://orcid.org/0000-0003-4749-1460
}

\section{RESUMEN}

En el presente artículo el autor explica cómo el fracaso del proyecto tupacamarista dejaría libre el camino para las ideas y el accionar de los criollos, y estos, por medio del uso privilegiado de la escritura serían los que dominaran el mundo de las ideas y, por ende, de los proyectos ideológicos. Siguiendo la ruta de las transformaciones del grupo criollo analiza su composición socio-cultural y sus ideas. Lo indígena pre-1781 ya no tendría posibilidades de resurgir, aun cuando el contingente criollo pierda consistencia, es decir, su capacidad como sujeto político ya sería irrelevante. Desde mediados del siglo XX, el campo ideológico por conquistar sería disputado por lo que quedaba del exiguo contingente criollo y por los elementos difusos dejados por el proceso de cholificación pos-migraciones internas y pos-reformas velasquistas. Posteriormente, la política fujimorista modificaría el papel de los intelectuales. Así, se configuraría así un inédito proceso conflictivo, de lucha por el poder político, económico, ideológico y simbólico; y por dar sentido a un país profundamente modificado por medio de nuevos sujetos de ideas.

PALABRAS CLAVE: intelectuales; nación peruana; bicentenario; nación; criollos.

\section{The intellectuals and the peruvian nation. Reflection on the eve of the bicentennial}

\section{ABSTRACT}

In this article, the author explains how the failure of the Tupacamarista project would open the way for the ideas and actions of the Creoles, and these, through the privileged use of writing, would dominate the world of ideas and, therefore, hence, of ideological projects. Following the route of the transformations of the Creole group, he analyzes its socio-cultural composition and its ideas. The pre-1781 indigenous would no longer have the possibility of resurgence, even when the Creole contingent loses consistency, that is, its capacity as a political subject would no longer be irrelevant. From the middle of the 20th century, the ideological field to be conquered would be disputed by what was left of the small Creole contingent and by the diffuse elements left by the process of postinternal migration cholification and post-Velasquista reforms. Later, Fujimori politics would modify the role of intellectuals. Thus, an unprecedented conflictive process would be configured, of struggle for political, economic, ideological and symbolic power; and for giving meaning to a deeply modified country through new subjects of ideas.

KEYWORDS: Intellectuals; Peruvian nation; bicentennial; nation; criollo people. 
a independencia del Perú debe ser entendida como un proceso y dos proyectos. Un proceso definido por el declive del imperio español, el crecimiento del poder del imperio británico, el surgimiento en las colonias americanas descontentas con su condición de tales, la Revolución Francesa y las ideas de la llustración. Estos serían factores que desembocarían en la necesidad de la separación de las colonias del imperio español y que envolverían tanto a los tupacamaristas como a los criollos. Al ser derrotado el proyecto indígena-popular y radical tupacamarista, los sectores que incluyó (indígenas, criollos pobres, afroperuanos, provincianos) se quedaron sin posibilidades de producir proyecto, acción política, pensamiento por medio de intelectuales orgánicos y liderazgo. Su fracaso dio paso a las posibilidades del proyecto reformista y elitista de los criollos quienes serían los que finalmente encabezarían la nueva república en 1821. No se trató de dos proyectos en pugna, pues mientras actuaba el tupacamarismo el proyecto criollo estaba muy en ciernes, con algunas manifestaciones intelectuales, sino de un proyecto que emergió cuando el otro había sido derrotado: el proyecto criollo se irguió desaparecido el proyecto tupacamarista. Esta sucesión, y no complementariedad, impidió que se constituyera una genealogía común, una historia compartida; no se constituyó una narración que uniera en un lenguaje común a los dos proyectos en una comunión de propósitos, siquiera simbólicos, aun cuando las diferencias hubieran sido, como lo fueron, sustanciales (Anderson, 1993).

He mencionado a los intelectuales por una razón fundamental: son ellos los encargados de producir ideas y debates acerca de la sociedad, de señalar sus problemas vitales y de diseñar el tipo de sociedad preferible (Adrianzén, 1987; 1990). Sus funciones sociales son de dar sentido a la vida colectiva, formular preguntas, reflexionar sobre quiénes integran la nación, así como buscar influir o participar en la política. Cuando se une la idea con la acción se producen importantes impactos reales. Es una equivocada propuesta sostener la inevitabilidad de la dicotomía entre la actividad intelectual y la acción política (Gouldner, 1980; Konrad\&Szelényi, 1981; Löwy, 1978; Bobbio, 1998). Su interpenetración es imprescindible, que significa cooperación y no subordinación de ninguna de las partes. Lo intelectual y lo político tienen su lugar en la vida social.

\section{2}

Una vez asegurado su poder en el nuevo Estado, el sector intelectual criollo no permaneció inmutable, sino que se fue modificando al compás de la lucha política, 
de los cambios sociales y también de las ideas que ingresan para variar el contenido del debate intelectual y político. Al carácter aristocrático de sus momentos iniciales le sigue la incorporación de elementos de la burguesía (limeña o provinciana, y que no era necesariamente blanca), luego el de algunos elementos plebeyos hasta que el original grupo criollo blanco-aristocrático pierde toda presencia para dar lugar a lo mestizo, aún de contornos muy imprecisos. Hacia mediados del siglo XX, el sector criollo va perdiendo influencia para ceder su lugar a lo mestizo plebeyo, a lo cholo y provinciano de clase media o pobre.

Las disputas de ideas y proyectos políticos que florecieron en el cuerpo criollomestizo se manifestaron de diferentes maneras en el afán por capturar el sentido de la vida social, entre autoritarios y democráticos; liberales y conservadores; elitistas y plebeyos. Pero se debe precisar que no existe una correspondencia exacta entre procedencia social-cultural y propuestas ideológicas. Muchas veces, intelectuales pertenecientes a una clase social o una procedencia cultural optan por otra clase y procedencia distinta a la suya, que complejiza más el análisis. De entre las diferencias sociales existentes debo destacar una en especial —en concordancia con los objetivos de la presente propuesta - es la posesión de la palabra escrita. Luego de la derrota tupacamarista, el orden colonial arrasó no solo con los rebeldes sino con su cultura (elementos religiosos, liderazgos sociales, incluso lecturas) y sus élites, que eran ilustradas y por lo tanto sabían leer y escribir. Comentarios reales del Inca Garcilaso se convirtió en una fuente de identidad (Montiel, 2010), y los edictos y proclamas evidenciaban el ejercicio de la escritura como importante para expandir su legitimidad social. El elemento indígena quedaría amputado de sus elementos generadores de autoconciencia y de formulación de proyectos políticos. La derrota militar fue también social y cultural. Entonces emergería el descontento de los criollos, que quedaron como los casi únicos poseedores de la escritura.

\section{3}

Conocer la función que los intelectuales han tenido, y tienen, en la república, hace ya 200 años, es importante, aunque ha pasado desapercibido en los análisis académicos. En este texto los coloco en el centro de estas reflexiones. La República del Perú no solo nació al amparo de los cañones, también lo hizo a la sombra de los debates de ideas. Entenderlos — las ideas y los debates—, aunque sea someramente, exige relacionar contextos, proyectos políticos y representaciones de intelectuales que surgen al compás de los problemas de la vida social (Coser, 1966; Znaniecki, 1944; Maldonado, 1998; Weber, 1988). He de ser esquemático, no solo por el extenso 
periodo sino también por la propia composición del llamado "sujeto intelectual" en el Perú, cuyas huellas en la vida nacional es permanente (Sanders, 1997).

Desde antes de la lucha emancipadora hubo una pregunta central, ¿qué somos? Es entonces cuando emerge un intenso debate doctrinario y de reflexión; se trata de un momento de crisis de la administración colonial que se mezcla con la inicial insatisfacción presente de distintos segmentos sociales peruanos (Rey de Castro, 2008). Hacia fines del siglo XVIII, el núcleo gravitante fue el levantamiento de Túpac Amaru II de 1781. Los criollos provenientes de la aristocracia fueron sorprendidos por la rebelión, pero no pudieron soslayarla, como lo evidencia el "Elogio" al virrey Jáuregui de José Baquíjano y Carrillo. Desde el destierro, un criollo jesuita arequipeño de clase media, Juan Pablo Viscardo y Guzmán, respaldaría la sublevación buscando apoyo de Gran Bretaña mediante el envío de cartas al Cónsul inglés de Udny. Después de la derrota de la rebelión tupacamarista, aparecería la fundamental "Carta a los españoles americanos", de 1799. En ella, Viscardo plantea algo inédito hasta entonces, la necesidad urgente de que las colonias se separen de la Corona española, afirmando además que sean los criollos quienes deben asumir el control de sus propios gobiernos. Luego de que el cacique cusqueño fuera derrotado por las fuerzas realistas, aparecería un grupo de intelectuales que fundaron la revista Mercurio Peruano (1791-1795) de la Real Sociedad Amantes del País. Miembros destacados fueron José Baquíjano y Carrillo, Hipólito Unanue, José Rossi Rubí, Jacinto Calero, Jerónimo Calatayud, Jacinto Calero Moreira, José Rossi Rubí, José María Egaña, entre otros.

Son tres los aspectos que es necesario destacar del grupo intelectual de los mercuristas. Primero, que como grupo sus integrantes marcaron diferencias críticas con la rebelión tupacamarista. Segundo, que estos pensadores se impusieron la obligación de conocer la geografía y lo que en ella había, de descubrir y analizar el paisaje, el clima y otros aspectos de la vida natural. Y tercero, que los mencionados intelectuales debían identificar un pasado heredado (ahí encuentran a los Incas) para poder definir los contornos de la nación en el presente. Explícita y conscientemente unen la historia con el momento actual para construir una continuidad temporal de lo que empezaban a identificar como el Perú, marcando sus distancias con el poder colonial. Los planteamientos de los mercuristas constituyeron un primer paso para construir una identidad autónoma pero no exclusivamente desde el Estado, sino también, y esto es importante, desde las élites criollas que gozaban privilegios.

La guerra por la independencia puso en debate - por medio del periodismo especialmente (Varillas, 2008) — otra pregunta trascendental: ¿cuál era el tipo 
de gobierno que deseaban los criollos de las élites? Se debe subrayar un hecho paradójico: si bien fue en el Perú que surgió la primera expresión seria de rebelión contra la metrópoli con la rebelión tupacamarista, fue el último en liberarse de la Corona. Esto se explica en gran parte porque las consecuencias de la sublevación cusqueña tuvieron profunda trascendencia, produciendo miedo en las élites coloniales quienes en adelante ejercerían un mayor control para prevenir nuevos movimientos insurreccionales. También porque el Perú era el virreinato más importante en la región y, por tal razón, el colonialismo se asentaría en nuestras tierras: el virrey Abascal se convertiría en el portaestandarte del fidelismo. Esta contradicción explica que en la naciente república se desarrollara un amplio debate acerca de la forma de gobierno más adecuada. Como es conocido, San Martín y Monteagudo pusieron en debate la idea la propuesta de la monarquía constitucional, que no significaba una ruptura total con el pasado colonial. La pregunta que surge es la siguiente: ¿postura realista o claudicación retrógrada?

Los liberales educados en el San Carlos, regido por Toribio Rodríguez de Mendoza, y que serían próceres de la independencia, que representaban a "la izquierda criolla" (Sánchez Carrión o Mariátegui, por ejemplo), defendían una posición radical: romper definitivamente con la dependencia de España u otra potencia. Sostenían que los peruanos podíamos gobernarnos sin necesitar ayuda externa. Para entonces, la composición casi exclusivamente aristocrática de las élites, ya experimentaba transformaciones. Sánchez Carrión era un hombre de clase media, de la burguesía, y no exhibía orígenes aristocráticos, así como Mariátegui. Quizás ello explique su posición no solo más radical, sino más sostenida en el tiempo, a diferencias de otros que en su proceso biográfico fueron cambiando de posturas frente al tema del tipo de gobierno.

Sería el grupo liberal el que tomaría el control del Estado durante el Congreso Constituyente de 1822, después que José de la Riva Agüero y Sánchez Boquete fracasara en la guerra de intermedios lo que permitiría la recuperación de los realistas. En el inicio de la república, serían los intelectuales quienes controlarían el poder en el Perú, confiados en que el verbo podía ir unido a la acción. Pero la fuerte arremetida española obligó a la representación congresal a convocar a Simón Bolívar, quien establecería la Dictadura vitalicia. Parece ser que cuando los intelectuales toman el poder, y luego de un primer momento fundacional marcado por el optimismo, adviene el desgobierno que deriva en gobiernos autoritarios o, simplemente, en dictaduras.

De manera ambigua, la independencia y la fundación de la república produjeron optimismo y desconcierto. Una representaría una continuación entre la colonia y 
la república en tanto intelectual asesor del poder. Legitimó tanto a virreyes como a libertadores. En tanto sabio reconocido, se puso a disposición de quienes controlaban el poder. Sin subjetividades, es posible afirmar que Unanue es fundador de un tipo de representación de intelectual: el de servir al poder gracias al conocimiento que porta, como asesor de la "central del poder", según expresión de Coser (1966).

El plan de constituir un Estado central entraba en conflicto con los poderes locales. Las instituciones provenientes del pasado colonial, ya no eran adecuadas para la nueva república, lo que obligaba a construir otras nuevas. Encarnación de esta crítica a la administración colonial fue Vidaurre y Encalada autor de Plan del Perú. (Filadelfia, 1927). Ante la ausencia de instituciones que pudieran organizar la lucha en el campo político, el ejército adquiriría relevancia. Ideológicamente, los pensadores criollos pensaron que el liberalismo se extendería por toda la nación, pero lamentablemente, el pensamiento existiría sin una vinculación orgánica con la vida social. En otras palabras, se podría resumir el contexto diciendo que había más liberalismo que liberales. La burguesía era aún muy "larvaria” (como le gustaba afirmar a José Carlos Mariátegui), y distaba de ser clase dirigente, como sí sucedía en Estados Unidos, Francia o Inglaterra, por ejemplo. La República del Perú nacería en medio de conflictos entre caudillos militares, lo que produciría anarquía política. Ello se expresaba en el hecho de que cada caudillo casi era capaz de organizar su propio Estado, aunque sea solo efímeramente, hasta que lo sucediera otro militar que en algún momento previo había sido su aliado.

El componente aristocrático del grupo dirigente criollo prácticamente había perdido el poder del primer momento. Por el contrario, la presencia de la burguesía urbana era la principal, y eso implicaba otra manera de pensar y de actuar políticamente. El siglo XIX sería pródigo en la aparición de censores y válidos, dicho de otra manera, los cuestionadores (usualmente legisladores) y los legitimadores (generalmente periodistas) de quienes encarnaban el poder, como lo ha estudiado Jorge Basadre (1978).

Una figura ejemplar en tanto fustigador del poder — de manera directa contra Agustín Gamarra-, por medio de sus discursos pronunciados desde su tribuna de congresista para defender la constitucionalidad, sería Francisco de Paula González Vigil, liberal y clérigo de reconocidas condiciones morales. En su discurso parlamentario de 1832, "Yo acuso", denunciaría a Gamarra por la violación a la Constitución; en este sentido, Vigil antecedería al escritor Emile Zola, defensor de los derechos humanos durante el emblemático caso Dreyfus, en Francia, en los años finales del siglo XIX. 
Con Vigil, el intelectual es legitimado como expresión de la conciencia moral pública y de los valores republicanos. Por sus calidades intelectuales y cívicas, sería nombrado director de la Biblioteca Nacional. Mientras tanto, el Perú seguía inmerso en la anarquía política y militar. No se podría afirmar que la democracia era una preocupación en el momento de dar forma al gobierno, es más, los golpes de Estado fueron el recurso apelado para resolver los permanentes conflictos políticos, y se sucederían continuamente, aunque ello no sería obstáculo para que en ciertos momentos el Estado se modernizara.

Los gobiernos de Ramón Castilla (entre los años 1855 y 1862) fueron momentos modernizadores al decretar la ley de la libertad de prensa, declarar la manumisión de los esclavos negros, fundar el servicio diplomático, abolir el tributo indígena, entre otras decisiones que justificaban cierto optimismo. Recordemos que había empezado la explotación del recurso guanero, cuyos ingresos sustentarías los gastos fiscales, así como daría lugar a fortunas familiares que originaría a una clase directora privilegiada oligárquica. Como liberal, Castilla se haría aconsejar por intelectuales liberales como José Gregorio Paz Soldán, José Gálvez, Juan García del Río. Como conservador, oiría los consejos del clérigo Bartolomé Herrera. Los intelectuales comenzaban a consolidar su papel en espacios cercanos al poder. Así, en la Dictadura de Mariano Ignacio Prado (1865-1867), se conformaría el llamado Gabinete de los talentos, integrado por Toribio Pacheco, José María Químper, José Gálvez, José Simeón Tejeda y Manuel Pardo. Los intelectuales devienen entonces en funcionarios, e inauguran en el país una nueva forma de influir en las esferas de decisión: los portadores de ideas conformando el núcleo donde se toman las decisiones de Estado. El Combate del 2 de mayo produciría una pasajera unidad, a ello se sumaría un clima de confianza ocasionada por el aumento de los ingresos fiscales, que Basadre denominó prosperidad falaz, que se produjo gracias al auge del comercio guanero.

Un miembro de ese sector oligárquico, Manuel Pardo, y otros intelectuales, como José Casimiro Ulloa, Francisco García Calderón Landa, y otros, publicaron en La Revista de Lima (1860) (Kristal, 1991) la idea de un Perú integrado gracias al tendido ferrocarrilero, y con la suficiente capacidad de explotar sus riquezas tanto agrícolas como mineras. Aunque interesante, fue incompleta, pues se trató de una propuesta elaborada desde la costa y desde arriba. El boom guanero pronto se disiparía del horizonte debido a la ausencia de una clase con capacidad de conducir al Perú por el camino del desarrollo, a lo que se sumarían los perjuicios ocasionados por la corrupción. 
Posteriormente, en 1871, quienes editaban La Revista de Lima fundarían el Partido Civil, pensado como la expresión en el terreno político de la burguesía guanera. Pardo sería elegido como Presidente del Perú y concluiría con el militarismo que copó la vida política desde los inicios de la república. Rápidamente, el civilismo se convertiría en el partido más influyente de la política peruana hasta, aproximadamente, los años 20 del siglo pasado. Fue un partido con programa, es decir, con una propuesta para desarrollar el país. Esto ejercería una seducción en intelectuales como Toribio Pacheco, Fernando Casós, Carlos Lisson, Luis Felipe Villarán, Francisco García Calderón Landa, Simeón Tejeda, entre los más destacados.

El comercio guanero generó riquezas, pero también negociados corruptos que jugaron en contra de los intereses nacionales. Surgiría entonces la voz prístina de un pensador que no tuvo miedo de denunciar los ilegales manejos de la inesperada riqueza: Mariano Amézaga, a quien se le conoció como "El santo hereje" (Garavito Amézaga, 1986) destacando su comportamiento ético como su consecuencia cívica. Este intelectual de tipo jacobino, cumplió con ser una especie de consciencia crítica de la nación; por sus críticas mordaces puede ser identificado con la figura del tábano, en tanto orientaba su voz y su pluma para incomodar y criticar sin cesar a los grupos corruptos que gobernaban.

El auge del guano constituyó una oportunidad perdida que concluyó dolorosamente con la Guerra con Chile (1879-1883), la que sacó a la superficie nuestras carencias. Es decir, que el Perú no era aun una colectividad, que importantes sectores de las élites privilegiaban intereses de grupo y no los de la nacionalidad; que amplios segmentos de la población, como los indígenas, los afrodescendientes, los amazónicos y los de origen asiático, no eran considerados parte del Estado.

Un Estado frágil, un territorio fragmentado y una población que no podía sentirse integrantes de una comunidad, fueron condiciones que derivaron en la catástrofe inevitable. La derrota obligó a repensarlo todo, pero no sin antes ejercer la catarsis.

Manuel González Prada surgiría para ejercer la denuncia del fracaso total de la república. Heredero de los ejemplos de Vigil y Amézaga, y ante los escombros dejados por la guerra, el pensador ácrata invertiría el objetivo de las acusaciones, daría una dirección opuesta a la tradicional flecha de las responsabilidades, denunciaría a los fracasados reales de la nación: las élites, no el pueblo. Su adversario literario e ideológico, Ricardo Palma, por el contrario, culpaba a los indios del fracaso por su falta de identidad como peruanos. González Prada trasladaría el lugar desde donde se llevaría a cabo la constitución nacional: ya no desde los privilegiados, sino desde las clases populares. Sus sermones cívicos buscarían personajes que por su integridad moral nos salvarían de las ruinas, a los honestos, y en esa búsqueda 
encontraría y relevaría la figura del héroe naval, Miguel Grau, así como depositaría su esperanza en los intelectuales portadores del conocimiento científico, así como reconocería su lugar prominente a los obreros e indígenas. González Prada encarnó el papel que su momento requería para tomar consciencia de los males nacionales: un intelectual disidente. Complementariamente, su descarnado diagnóstico sobre la quiebra nacional echaría las bases sobre las cuales posteriormente florecería el pensamiento radical. A todo esto, es necesario subrayar algo sustancial: era un criollo de origen aristocrático que se había desclasado y que ponía su voz a disposición de las clases desposeídas que no habían podido dar forma a una expresión propia desde la derrota tupacamarista; necesitaban que otros hablaran —y escribieranpor ellas.

Para entonces lo criollo ya había sufrido transformaciones fundamentales al haber incorporado a pensadores de distinta procedencia social y cultural como los afroperuanos Palma y Casós. Según casos y momentos, algunos de los intelectuales mantenían lazos de afinidad intelectual e ideológica con los supérstites representantes de las élites criollas de la burguesía, mientras que en otros momentos representarían proyectos disímiles, como se vería después.

\section{4}

El tiempo posterior a la guerra de 1879 mostraría la centralidad de la cuestión del indio, que en verdad era el de los gobernantes, quienes no tuvieron interés de integrar al habitante de los Andes a la nacionalidad. El tema indígena daría el contexto y el fondo a las reflexiones producidas por los pensadores sociales; estos sabían que no podía haber nacionalidad sin resolver las condiciones denigrantes del habitante andino. El enfrentamiento entre Iglesias y Cáceres concluiría con la victoria de este, instaurando el gobierno de la Reconstrucción Nacional. Su aureola de héroe y de patriota atraería a pensadoras como Mercedes Cabello de Carbonera y Clorinda Matto de Turner, quienes elaborarían una interpretación del país desde el lugar de las mujeres, de los obreros y de los indígenas; así como introducirían temas como la lectura y la educación, fundamentales en la visión moderna y positivista de su tiempo. Estas mujeres intelectuales y otras (como Juana Manuela Gorriti, María Jesús Alvarado, Teresa González de Fanning, por mencionar solo algunos nombres) serían parte de una promoción que desde fines del siglo XIX e inicios del XX conquistarían las letras y el pensamiento nacionales (Denegri, 2004).

Luego de la debacle total experimentada por el país post-1879, la vida nacional experimentaría uno de sus momentos más lúcidos. Después del triunfo de Cáceres 
sobre Iglesias, se desataría la guerra civil de 1895 que enfrentó al héroe militar contra Nicolás de Piérola, que encabezaría la Coalición Nacional (de civilistas y demócratas, antiguos enemigos políticos). Cáceres sería derrotado y se daría paso al tiempo dorado de la oligarquía peruana (1895-1919). El gobierno de Piérola aprovecharía el crecimiento del comercio internacional e impulsaría la actividad agro-exportadora. El optimismo se tradujo en intelectuales como Ricardo Palma, Leonidas Yerovi, Joaquín Capelo, Guillermo E. Billinghurst, Alberto Ulloa, Luis Fernán Cisneros, Alberto Ulloa Cisneros, Abelardo "El Tunante" Gamarra, José María de la Jara, Santiago Giraldo, Pedro Zulen, Dora Mayer, y muchos más. Se experimentaría un tiempo prolífico en discusiones ideológicas. En cierta forma, el grupo criollo se democratizaría con el ingreso de intelectuales mujeres y de aquellos cuyas familias procedían de nacionalidades distintas (italiana, alemana, inglesa, china), así como de mestizos populares, provincianos o limeños y plebeyos que convivían — de manera no necesariamente armoniosa - con elementos de una burguesía de clase media, comercial-exportadora, y de una burguesía industrial. Posteriormente, sucesivos grupos generacionales de intelectuales y desde distintos postulados filosóficos, políticos e ideológicos, contribuirían al desarrollo de diversas disciplinas, así como buscarían ofrecer explicaciones serias sobre la realidad nacional.

Los positivistas constituirían un grupo compuesto por pensadores como Manuel Vicente Villarán, Joaquín Capelo, Javier Prado y Mariano H. Cornejo: criticaban las plataformas sobre las cuales se había erigido la república, sea desde de la educación, de la organización económica o de la institucionalidad política; al mismo tiempo, analizaban la conformación de las comunidades indígenas y otras áreas de la vida social como la laboral. El propósito de estos intelectuales era modernizador, y mesocrático en algunos de sus integrantes. Gran parte de sus reflexiones abordaría el "problema de las razas" (como la tesis Clemente Palma sobre las razas, texto representativo por su visión prejuiciosa de las diferentes poblaciones nacionales), y proponía incentivar la inmigración de poblaciones europeas, a las que consideraban superiores.

Por su parte, los intelectuales positivistas comenzaron las reflexiones sobre el papel de los trabajadores y de los indígenas en la vida peruana. No se debe omitir que algunos de ellos fueron fundadores, con Pedro Zulen, Joaquín Capelo y Dora Mayer de la importante Asociación Pro-Indígena (1909-1916). Pero antes, un diputado puneño de ideas libertarias, Santiago Giraldo, editaría una revista predecesora del Deber Pro-Indígena llamada El Indio. Se puede observar signos inocultables de la preocupación sobre el indio, que absorbía las energías reflexivas de aquellos años. 
Aparentemente, el estilo de vida oligárquico había encontrado el camino a la felicidad, pero la poderosa presencia de abusivos poderes locales (gamonalismo o feudalismo andino), era un obstáculo para poder modernizar el Estado y construir una vida nacional integrada. Fracciones de las propias élites disputaban entre sí. Aprovechando esas grietas, aparecería el populismo en el Perú que sería representado por Guillermo E. Billinghurst en el año 1912 (Gonzales Alvarado, 2005). Este empresario salitrero se enfrentaría a todos los poderes, como el ejército, los poderes locales, la iglesia católica, y el mismo parlamento. Uno de sus más influyentes asesores sería Mariano $\mathrm{H}$. Cornejo, si bien de pensamiento positivista y modernizador, no necesariamente democrático. Encarna la figura de intelectual como asesor del poder, representación que en el Perú inauguró Unanue. Por la novedad que portaba, Billinghurst pudo atraer a muchos jóvenes intelectuales: Abraham Valdelomar, Luis E. Valcárcel, Carlos Concha, y otros, lo apoyaron con entusiasmo. Algunos pertenecían a élites provincianas y otros provenían de la clase media baja; no todos habían concluido sus estudios universitarios ni tenían títulos, incrementando la multiplicidad de lo criollo popular. Pero el afán de renovar la vida nacional se vería postergado debido al golpe de Estado del año 1914. El balance del fracaso lo expondría Víctor Andrés Belaunde en su imprescindible discurso "La crisis presente" de ese mismo año, y el que su compañero de generación, José de la Riva Agüero, calificaría como el punto de inicio para la conformación del verdadero partido liberal en el Perú.

Se ha hecho referencia a destacados intelectuales pertenecientes a la generación del 900 (Gonzales Alvarado, 1994), de manera específica los que constituyeron el grupo arielista: Belaunde y Riva Agüero, José Gálvez Barrenechea, los hermanos Francisco y Ventura García Calderón y Julio C. Tello, entre otros. Aunque algunos de ellos provenían de familias antiguas y de estatus social, para entonces, salvo Riva Agüero, ya eran integrantes plenos de la burguesía criolla peruana. Estos intelectuales propusieron interpretaciones novedosas de la vida nacional aportando sus reflexiones desde distintas disciplinas. En 1907, Francisco García Calderón publicaría, en París, la primera reflexión integral de nuestro país: El Perú contemporáneo. Belaunde continuaría dicho interés con su libro La realidad nacional, de 1931, en franca polémica con 7 ensayos de interpretación de la realidad peruana de José Carlos Mariátegui, de 1928. También en 1931 Jorge Basadre entregaría al lector su importante Perú, problema y posibilidad. Algunos años después, Belaunde propondría una visión del Perú desde la filosofía: Peruanidad.

Por otra parte, Tello fundaría la arqueología peruana, y Riva Agüero renovaría el debate académico cuando ofreció su profunda revisión conceptual tanto en el 
terreno de la crítica literaria como en el de las indagaciones históricas (Carácter de la literatura del Perú independiente, de 1905, y La Historia en el Perú, de 1910). Asimismo, Ventura García Calderón publicaría a nuestros clásicos literarios en Europa, que serían fundamentales para los futuros estudiosos interesados en podrían comprender el derrotero cultural del Perú. Todos estos intelectuales no solo pretendieron transformar la vida nacional, también quisieron hacer vida política, pero en este terreno no tuvieron éxito, pues las élites oligárquicas los boicotearon.

Los arielistas trataron de señalar que la promesa de la nacionalidad todavía era una deuda por saldar y, en ese sentido, formular propuestas para asimilar al indígena a la nación pero solo como fuerza de trabajo y soldado; a esto sumaron su convencimiento sobre las bondades del mestizaje en la constitución del "alma nacional" $y$, con variaciones, sustentaron la necesidad la inmigración de razas superiores europeas con el fin de "asimilar"al indígena. Desde la otra orilla, el filósofo espiritualista, Alejandro O. Deustua, afirmaba que la raza indígena era una sin futuro. En resumen, los intelectuales arielistas fueron la expresión de la bella época en el Perú, que en 1919 Augusto B. Leguía acabaría cuando ingresó al poder.

El oncenio leguiista fue un proyecto modernizador, pero también autocrático (Planas Silva, 1994). El asfaltado y la expansión de la ciudad fueron evidentes, asimismo las clases medias se fortalecieron, y los intelectuales adquirieron un brillo inusitado: son los años de José Santos Chocano, Valdelomar, Valcárcel, Cornejo, por ejemplo. Por otra parte, las clases populares obtuvieron un protagonismo que antes no habían podido ostentar, y, dentro de tal contexto, surgirían proyectos políticos e ideológicos radicales. La cobertura educativa se amplió y con ella la apropiación de la palabra escrita e impresa.

Es un tiempo de gran florecimiento de ideas sobre diversos temas: lo indígena y lo mestizo (Luis Alberto Sánchez, José Carlos Mariátegui), la nacionalidad (Belaunde), la literatura nacional (José Gálvez, Riva Agüero, Sánchez, el propio Mariátegui), la revisión histórica (Raúl Porras Barrenechea, Jorge Guillermo Leguía, Jorge Basadre), las comunidades indígenas (Hildebrando Castro Pozo, Manuel Vicente Villarán) y la educación (José Antonio Encinas), entre otras preocupaciones propias de pensadores atentos a las tareas pendientes de la realidad nacional.

La palabra impresa también fue sustancial en la prensa, la que se colmó de intelectuales-periodistas, especialmente después de la guerra de 1879. En diarios y revistas aparecerían las primeras expresiones de ideas que pronto serían centrales en el pensamiento, como el psicoanálisis, representado por Honorio Delgado. Diarios impresos como La Prensa, Variedades, El Comercio, La Crónica, Mundial, 
Amauta y muchas más se convertirían en vehículos de reflexiones con ambiciones totalizadoras.

La palabra escrita experimentaría un auge nunca visto gracias al estilo pulcro de escritores como Valdelomar, Leonidas Yerovi, Luis Fernán Cisneros, Federico More, Mariátegui, Ángela Ramos, Magda Portal, Alberto Ulloa, Carmen Saco. Asimismo, surgiría el periodismo de divulgación científica con Óscar Miro Quesada-Racso; y todo esto sin olvidar la palabra escrita de combate de los trabajadores anarquistas. Por otra parte, las provincias serían parte de este boom contribuyendo al debate nacional, como el Boletín Titikaka de Puno, y otros núcleos de intelectuales como los formados en Trujillo, Chiclayo, Arequipa, Cusco, Huancayo.

El contingente criollo se iría diluyendo por acción de la mayor presencia de las provincias y de personajes que incursionan en el mundo de la palabra escrita sin cumplir los requisitos formales del proceso educativo: Valdelomar no concluyó ninguna profesión, Eguren no realizó estudio universitario alguno, Haya de la Torre no se tituló y Mariátegui, especialmente, fue un autodidacta que no terminó siquiera los estudios primarios. Es decir, la corrosión del grupo criollo provino desde los márgenes de la modernidad subvirtiendo las reglas que había tratado de imponer. A ello se debe sumar el factor ideológico-político, pues aparecerían fuerzas políticas novísimas, portadores de idearios revolucionarios.

Durante el oncenio surgirían las más importantes propuestas ideológicas de los partidos de masas bajo la influencia de Mariátegui y Haya de la Torre (Landázuri, 2015; Flores Galindo, 1980). Más allá de sus discrepancias, para ambos era impostergable la refundación de la república para alcanzar la definitiva constitución de la nación, la misma que debía realizarse a partir de un hecho fundacional radical como es la revolución (a los dos personajes mencionados habría que agregar a Valcárcel y su mesianismo andinista). Pero, además, sumaban un giro crucial: la nación deberá constituirse desde las clases populares, siguiendo una línea de pensamiento del maestro de la nueva generación, González Prada. Se trata de una manera distinta de concebir a la nación. Dentro de esta tradición de cuestionamientos, Mariátegui y Haya de la Torre no dudarían en señalar a las élites oligárquicas como las responsables de la no realización de la nación peruana.

La temprana muerte de Mariátegui, ocurrida en 1930, dejaría inconcluso su proyecto; Haya de la Torre, por su lado, iniciaría la organización del APRA. Aun cuando el líder aprista señalaba desdeñosamente a Mariátegui como "solo un intelectual", él mismo sería prolífico en proveer de ideas a la actividad política. Si el Amauta fue un intelectual que ingresó a la política, Haya de la Torre sería un líder carismático con un muy bien definido proyecto. 
En la célebre polémica Mariátegui-Haya de la Torre se resumen algunos de los prejuicios mantenidos sobre la figura y el oficio del intelectual: incapaz de la acción decidida y utópico. La actividad intelectual es vista como una sub-categoría de la política, prejuicio que el intelectual aun no ha podido remontar totalmente.

\section{5}

El autoritarismo de Leguía sería sucedido por la dictadura de Luis M. Sánchez Cerro en 1930. Sería una nueva etapa sombría en la vida política peruana. El presidente golpista, después de convocar a un Congreso Constituyente, sería asesinado, y asumiría el poder otro soldado: Óscar R. Benavides. Pero lo que debe ser rescatado dentro de un ambiente sombrío son los debates que se sucedieron en el Congreso entre comunistas, apristas y socialcristianos de alto contenido doctrinario; fueron intercambios de ideas y contrastación de proyectos políticos que preludiaron el momento de la represión y el exilio. En ese contexto surgiría la figura de Luis A. Flores, vehemente fascista, que daría forma a una agrupación política llamada Unión Revolucionaria (Molinari Morales, 2009; 2017). No se debe perder de vista que el fascismo ya era compartido por un grupo de importantes intelectuales, como Carlos Miro Quesada, Riva Agüero, Abelardo Solís (antes cercano a Mariátegui) y, momentáneamente, Dora Mayer. Por otra parte, en 1932, la Universidad de San Marcos había sido clausurada, hecho que gravitaría en el futuro en los terrenos de la producción y del debate de ideas. Como es usual, la dictadura política necesita de la sujeción de la inteligencia para subsistir. En resumen, dos militares, Sánchez Cerro y Benavides, hegemonizarían la vida política en la década del 30, y sus consecuencias no pudieron ser más perversas para el pensamiento contestatario, el cual necesitaría tiempo para recuperar su lugar e influencia.

Muy pronto, la sociedad peruana experimentaría una transformación radical e inesperada. En efecto, desde mediados de los años 40 del siglo XX y en adelante ocurrirían las migraciones del campo a la ciudad; al principio tímidamente pero luego, desde los años 50, especialmente bajo el gobierno de Manuel A. Odría (19481956), sería de manera multitudinaria. Recordemos, son los años de la post-guerra, de la guerra fría, del estallido de la guerra de Corea, pero también de una acotada modernización de la burguesía industrial peruana que necesitaba de mano de obra barata. Así, es construido un discurso, el del mito de El Dorado: Lima, la capital de la república, vista como el lugar en donde era posible realizar todos los sueños. Simultáneamente, implicaba la erosión radical del sector criollo y del mundo andino feudal, así como el fortalecimiento de la clase media, el declive de los hacendados 
y, al mismo tiempo, la centralidad de lo campesino-indígena como un actor social en pos de sus derechos ciudadanos. La burguesía conseguiría la deseada mano de obra abundante y barata, pero no advirtió la democratización social que advenía. El flujo enorme de peruanos hacia Lima especialmente, implicó la demanda y el acceso a la educación formal y, por lo tanto, la posesión de la lectura y de la escritura, lo que sería un hecho profundamente transformador en sí mismo.

En este momento de expansión significativa de las clases medias urbanas aparecerían fuerzas políticas con idearios, propuestas de desarrollo y cierta concepción de la nacionalidad: los llamados partidos programáticos. Los más importantes fueron la Democracia Cristiana, dirigido por abogados como Héctor Cornejo Chávez, Ernesto Alayza Grundy y Mario Polar Ugarteche; el Movimiento Social Progresista, aunque pequeño congregó a valiosos pensadores como Francisco Moncloa, José Matos Mar, Augusto Salazar Bondy, Alberto Ruiz Eldredge, que luego dieron forma al Instituto de Estudios Peruanos; Acción Popular que además del filósofo Francisco Miro Quesada tuvo al escritor Ciro Alegría; y el Partido Popular Cristiano (fundado a partir de su ruptura con la DC) (Gonzales Alvarado, 2016:32). Todos los grupos políticos mencionados tenían en común buscar implementar reformas antioligárquicas y modernizadoras, fortalecer y nacionalizar el Estado, incrementar el proceso industrializador y eliminar el régimen semi-feudal presente en el campo. Asimismo, postulaban por el fortalecimiento de una clase dirigente técnica y bien capacitada, aunque sin dejar de lado el proponer reflexiones sobre el ser humano: había un sentido humanista en sus propuestas ideológicas.

Una consecuencia trascendental de las migraciones campo-ciudad fue que hirió de muerte al orden feudal; otras dos consecuencias fueron el permitir el encuentro democratizador de diferentes culturas en la zona costera y el de brindar nuevas condiciones para la constitución de la nacionalidad, aun cuando desde el Estado la presencia del campesino-indígena buscaría ser neutralizada. En efecto, Odría pondría en funcionamiento el Instituto Indigenista Peruano (IIP) que ya había sido fundado por Valcárcel, pero que recién entraría en funcionamiento por Encinas.

El IIP significó - entre otras cosas - una museificación del habitante andino buscando despojarlo de sus posibles intereses políticos que la izquierda sí trataría de profundizar. En este momento de la discusión adquiriría cada vez mayor legitimación intelectual y política la idea del llamado mestizaje popular, en otras palabras, de la cholificación. José Varallanos y Aníbal Quijano serían los primeros intelectuales en llamar la atención sobre este proceso, abriendo un nuevo campo de discusión académica y política. A esta nueva manera de entender la construcción de lo nacional, que debía ser popular, se sumaría la concepción de que el poder alcanzar la 
realización de la nación pasaba necesariamente por la revolución. Habían algunas señales que sostenían el realismo de esta convicción: en el plano externo, el triunfo de los guerrilleros de Cuba; también las luchas de liberación nacional, en las antiguas colonias de los países europeos; y en el plano interno, las guerrillas de los años 60 encuentran su origen de legitimidad ideológica, en las ideologías aparecidas en la segunda y tercera década del siglo XX, es decir, del aprismo y del mariateguismo.

Militantes convencidos de la idea de la revolución, como Javier Heraud, Luis de la Puente, Héctor Béjar, Manuel Lobatón, entre varios más, tomaron la decisión de internarse en las montañas y en la selva para dirigir la revolución que destruiría el Estado por no representar a la verdadera nacionalidad peruana, la que se expresa desde el pueblo. Los intelectuales guerrilleros serían derrotados con facilidad, pero sus ideas tuvieron una mayor permanencia en el tiempo, incluso se podría afirmar razonablemente que sus planteamientos adquirirían más fuerza en la década posterior cuando algunas de sus reivindicaciones más importantes - como la reforma agraria, por ejemplo—-, se volverían políticas de Estado bajo el reformismo militar del velasquismo en los años 70 .

Sería un novelista quien encarnaría las transformaciones mencionadas: José María Arguedas, quien en los años 30 había dado a conocer cuentos de contenido indigenista, como Agua, y moriría en 1969 tras proponer una nueva lectura del país plasmada en su novela póstuma titulada significativamente El zorro de arriba y el zorro de abajo. Esta novela sería sumamente importante porque haría visible la confluencia multicultural que se estaba produciendo en las ciudades de la costa peruana. Como en otros casos, la ficción literaria se adelantaría a la práctica política, pues, efectivamente, algunos lustros más tarde, la política dejaría de ser pensada en términos de exclusión de clase para dar paso a una reflexión sobre un sujeto político compuesto por múltiples determinaciones tanto culturales como sociales, y no solo las provenientes de las bases económicas.

La influencia y centralidad de las migraciones en la constitución nacional serían estudiadas por intelectuales como José Matos Mar, Norma Adams, Jürgen Golte, José Guillermo Nugent, Carlos Iván Degregori, y muchos más. El punto de partida en común que tienen es que la verdadera nación se constituye desde las iniciativas y experiencias de las clases populares. Se trata de una época en la que son privilegiadas dos urgencias: por un lado, la reforma agraria y, por otro lado, la industrialización que permitiera a la economía peruana ser independiente de las potencias extranjeras. Ambas urgencias tenían ya antecedentes en los debates producidos algunas décadas atrás. 
Para comprender la urgencia de la reforma agraria no solo debemos recordar a Mariátegui, Haya de la Torre o Solís, sino también a Víctor Andrés Belaunde. Si los tres primeros de los mencionados constituían lo que se puede definir como proyecto radical, el último de los nombrados era claramente reformista, de cuya pertinencia quiso convencer, inútilmente, a las élites gobernantes. Ya en los años 50, Pedro Beltrán y el diario del cual era propietario, La Prensa, también alertaron sobre la necesidad impostergable de reestructurar el agro, igual haría el político Fernando Belaunde Terry (sobrino de Víctor Andrés Belaunde) durante su primer gobierno. Estos planteamientos nos informan que ya existía consenso en diversos e importantes sectores intelectuales y políticos de que el mundo agrario debía ser transformado. Sobre la otra urgencia, la de la industrialización, también había una tradición de larga existencia igualmente desatendida. Un primer caso relevante fue el del empresario salitrero, Billinghurst, quien desde finales del siglo XIX sostenía que el Perú debía dejar de depender de Gran Bretaña afirmando que los mismos peruanos podían producir lo que necesitaban. Por su parte, Belaunde abogaba por la constitución de una clase media (es decir, burguesía nacional) para combatir, según sus palabras y las de sus compañeros arielistas, el "vasallaje económico". Para finalizar las líneas sobre este tema, se debe incluir a Haya de la Torre y su libro El antimperialismo y el APRA, en el que se mostraba enfático en la convicción de la necesidad de desarrollar la industria nacional desde políticas emanadas por el Estado. Ambas demandas urgentes, reforma agraria e industrialización, solo se llevarían a cabo, parcialmente al menos, durante el reformismo militar de Juan Velasco Alvarado (1968-1975).

No obstante sus falencias, el velasquismo es importante en la historia del Perú, pues representó un quiebre, cerró una época y abrió otra. Este carácter se expresaría en la seducción ejercida sobre una buena parte de la intelectualidad de la época, sobre intelectuales de talante reformista y anti-oligárquico, y que procedían de diversas tradiciones ideológicas y adscripciones políticas (Martín Sánchez, 2002). Carlos Delgado sería el principal ideólogo de las reformas velasquistas, y provenía del aprismo; a él se sumarían otros intelectuales provenientes del comunismo, del social-cristianismo, del social-progresismo y del reformismo en general, como Cornejo Chávez, Héctor Béjar, Carlos Franco, Salazar Bondy, Hugo Neira, Mario Villarán, entre otros. Todos estos intelectuales (y políticos), y aun con las divergencias que evidentes entre sí, contribuyeron a crear un cierto consenso sobre la necesidad de efectuar cambios importantes y de acabar con el caduco régimen oligárquico.

La reforma agraria y la inmigración a la capital fueron dos hechos que permitieron la ciudadanización de los campesinos e indígenas dado que les permitieron 
liberarse de las condiciones de servidumbre en las que vivían en las haciendas; mientras que la política reformista en torno al desarrollo industrial dignificó al obrero y trabajador. En términos sociales, ambos hechos impulsaron una significativa democratización social, aunque en materia de política económica constituyeron un fracaso. Más allá de estas objeciones y cuestionamientos válidos, el velasquismo constituyó la apertura de un nuevo momento en el debate de ideas en el país, en el que se pudieron discutir aspectos básicos como el de si la república había cumplido con la promesa de conformar una nación, de considerar a todos los peruanos como ciudadanos o si había que releer la historia para proyectarnos al futuro.

\section{6}

La dictadura velasquista y el exilio fueron responsable de una obra escrita en México y con pretensiones totalizadoras: Clases, Estado y nación en el Perú de Julio Cotler, aunque pesimista por considerar que cambios sustantivos no se habían hecho durante la república. Cotler pertenecía a las primeras generaciones de sociólogos, al igual que Aníbal Quijano y Ernesto Yepes del Castillo. Con las reformas velasquistas la nueva profesión adquiría relevancia, y las nuevas promociones a las que pertenecerían César Germaná, Sinesio López, Guillermo Rochabrún, Gonzalo Portocarrero, tomarían como reto explicar el nuevo país que emergía bajo dichos cambios.

Fue durante el velasquismo cuando se conmemoraron los 150 años de la independencia, ocasión oportuna para discutir si la independencia fue conquistada por los peruanos o concedida por ejércitos extranjeros. Hubo intelectuales, en general historiadores de izquierda que afirmaban que la independencia fue concedida (especialmente Heraclio Bonilla); sostenían acertadamente que los peruanos aún no conformábamos una nación y que ella recién se podría materializar gracias a la revolución, como ya se sostenía desde fines de los años 20. Por su parte, los intelectuales reformistas o conservadores, afirmaban que había valores heredados que le daban identidad a la nación.

Evidentemente, la desaparición del régimen oligárquico abría nuevas posibilidades a la burguesía modernizadora peruana, pero lo curioso fue que ni la izquierda ni la derecha pudieron reconocer la nueva realidad que en el propio bien de ellas había abierto el reformismo velasquista. Actualmente, la izquierda ha ejercido la auto-crítica con relación a su oposición sin matices al reformismo velasquista; la derecha no solo sigue en estado de negación, sino que ha radicalizado su oposición al velasquismo, muchos de sus intelectuales siguen polemizando con el finado militar como si nada hubiera cambiado en el Perú. Más allá del fin del velasquismo, lo que 
quedaría en el debate ideológico, político y académico es la preocupación sobre el problema nacional, y que cubriría la década de los 80 , especialmente entre los que se adscribían a la izquierda. Por su parte, los intelectuales conservadores o reformistas se inhibieron de participar en el debate público al respecto, se aferraron a valores tradicionales y dejaron de ser importantes en el estudio de la contemporaneidad.

La izquierda también tendría sus dificultades para adecuarse al presente Sus intelectuales, inscritos en la tradición revolucionaria, aceptaron casi obligados a la democracia en 1980, aunque siempre con el carácter de provisional. La irrupción de Sendero Luminoso sería cataclísmica y derrumbaría sus aprensiones respecto del régimen constitucional. La feroz violencia que portaban las acciones militares del senderismo, además de su dogmatismo, ocasionaron un enfrentamiento armado con el ejército que aniquiló miles de vidas y destruyó buena parte de las precarias bases de la convivencia nacional. Ante todo esto, surgirían preguntas clave: ¿la revolución era realmente la vía para la construcción de la nación?, ¿cuál era espacio que debía ocupar el marxismo en la interpretación y el conocimiento de la realidad peruana? El resultado en el campo socialista fue un interesante debate tanto al interior de Izquierda Unida (1980) como en el campo intelectual (Gonzales Alvarado, 2106:36).

Dentro de IU aparecería un grupo de intelectuales orgánicos que serían conocidos como zorros, en virtud de la revista que editaban: El Zorro de Abajo (1985-1987), cuyos miembros más destacados serían Rolando Ames, Sinesio López, Carlos Iván Degregori, Nicolás Lynch, Jorge Nieto, Juan Abugattas, Manuel Córdoba (Gonzales Alvarado, 1999). Con sus ideas se colocaron en la vanguardia dentro del pensamiento de izquierda en el Perú aceptando a la democracia como sistema político e incorporando otras vertientes y tradiciones (como la liberal) a su núcleo de pensamiento, como el liberalismo político e ideológico, y trataron de elaborar una visión distinta de la realidad nacional; este sería el primer paso que los llevaría a abandonar la fe inicial en el marxismo.

La ruptura de IU ocurrida a inicios de 1989 sería fundamental para que el proyecto de los zorros fuera derrotado. En tanto intelectuales orgánicos buscaban con afán al sujeto político. Dentro de la propia izquierda, pero al frente de ellos, se encontraban los intelectuales que componían el grupo Márgenes, como los historiadores Alberto Flores Galindo y Nelson Manrique, el sociólogo Gonzalo Portocarrero, el crítico de arte Gustavo Bunntinx, la internacionalista Inés García, entre otros. Sostenían aún la pertinencia de la revolución, pero quedaron encerrados en una disyuntiva: no aceptar la democracia y críticar al senderismo. Fue entonces que aparecería el libro del Flores Galindo, Buscando un Inca, vinculando mitos andinos 
con la revolución como estrategia para interpretar la historia del Perú. Surgiría un neo-indigenismo que tuvo poco tiempo de vigencia.

A nivel nacional, la ruptura de IU se sumó el desastre del gobierno aprista, abriendo brechas en un campo que se puede llamar reformista de izquierda, permitiendo el surgimiento legitimado del pensamiento liberal que hasta entonces había pasado desapercibido. Un experto-ideólogo como Hernando de Soto, y un escritor-ideólogo como Mario Vargas Llosa hicieron posible que la derecha recabara prestigio político e ideológico. De Soto, junto a Enrique Ghersi y Mario Ghibellini, y apoyados en literatura académica de origen izquierdista, en el libro El otro sendero, dieron forma ideológica a un sujeto, el informal, erigiéndolo como base de una deseada revolución económica que acabaría con el mercantilismo con una burguesía rentista. Inteligentemente, los mencionados autores logran realizar una operación desconocida hasta ese entonces en la derecha: mantener la idea de la construcción de la nación desde arriba pero apelando a un sujeto popular. Con estos intelectuales y con dicho título nacería el proyecto de una derecha popular que luego el fujimorismo buscaría encarnar políticamente. Más tarde, El misterio del capital de De Soto - libro de carácter menor pero importante para complementar la propuesta liberal-, se completaría a idea liberal sobre la realidad peruana. Por su parte, el aprismo haría mutis intelectual, no podía ser de otra forma, pues había dejado de tener pensadores. La propuesta ideológica liberal fue llevada a la política con Vargas Llosa, quien en las elecciones de 1990 se enfrentaría al tecnócrata Alberto Fujimori, quien triunfaría. El escritor-ideólogo abandonaría la plaza pública y retornaría a su escritorio de literato (Vargas Llosa, 1993).

En la actualidad, el informal adquiere rostro de emprendedor, elogiado por el liberalismo o neo-liberalismo; incluso se ha vuelto en casi un sentido común. Lo curioso es que el alabado emprendedor no hubiera sido posible sin las reformas del velasquismo, a las que la derecha liberal siempre ha rechazado. Durante los años 90, es decir, los del fujimorismo, se produjo la significativa desvinculación de los intelectuales del poder. Dentro de un régimen político que rechazaba la política y por ende la necesidad de representación de los intereses ciudadanos, una cúpula controló el poder obstaculizando mayores conquistas democráticas. El personalismo de la política devino dictadura, y esta cobijó altos grados de corrupción. Al mismo tiempo, moldeó un tipo de ciudadano competitivo, individualista y desentendido de los asuntos públicos. A ello contribuyó la retracción de la vida pública que había ocasionado Sendero Luminoso, causando terror en la población y deslegitimando a la democracia. 
En cuanto al problema de los intelectuales, en los años 90 el campo cultural se modificaría sustancialmente, dejando atrás definitivamente la herencia criolla (con todas sus modificaciones ya vistas) que había predominado durante toda la vida republicana hasta entonces. Lo cholo, queriéndolo o no, previendo o no sus consecuencias, ocuparía progresivamente los espacios que antes había poblado el contingente criollo y aparecerían intelectuales, comentaristas, libros y reflexiones de académicos que provienen de tradiciones completamente diferentes entre sí y que se harían ostensibles en el siglo XXI. Mientras se iba macerando esta nueva realidad, los años 90 encumbraron a los tecnócratas. Ante ello, los intelectuales de izquierda trasladaron gran parte de su actividad en las ONG y en la actividad periodística, desde esos espacios cumplieron su papel de crítica al sistema político autoritario y corrupto. Los debates producidos en dicho tiempo guardarían un tono básicamente político, publicando libros sobre el autoritarismo o la dictadura del fujimorismo (Nicolás Lynch, Martín Tanaka,), también sobre la anti-política (Degregori, Romeo Grompone) y la democracia (Carlos Franco): "La preocupación central giró sobre la existencia de condiciones para que el fujimorismo pudiera ser derrumbado, lo que finalmente ocurriría en el año 2000, no por la acción de las masas sino por un vídeo (los Ilamados vladivideos)" (Gonzales Alvarado, 2016:38). Los tecnócratas liberales no dudaban en participar de diversas maneras en el gobierno; los intelectuales liberales fustigaban el que las libertades civiles hubieran sido subsumidas a favor del poder político pero apoyaban el modelo económico: demandaban democracia, sí, pero a condición de mantener la forma de concebir la economía, como sostiene Jaime de Althaus en su libro La revolución capitalista de 2007. Otros, como Vargas Llosa en La civilización del espectáculo, de 2012, legitimaban el modelo económico, aunque criticando la cultura que emana de él.

La vuelta a un gobierno constitucional en 2001 nuevamente abriría al intelectual las puertas para influir en el poder, también para adquirir una presencia mayor en los medios de comunicación, y utilizar profusamente las redes sociales. Pero frente a ellos, la academia, en tanto el espacio privilegiado para la reproducción de los intelectuales como sujetos sociales, ha quedado profundamente debilitada cuando no simplemente corrompida con la creación de las universidades-negocio. De esta manera, el campo natural de la producción de ideas y debates ha sido reducido y debilitado profundamente. Los medios de comunicación ocuparon, aunque de modo distorsionado, ese espacio.

Aun así, existen algunos temas que ya son parte de la consciencia pública: la nación es concebida como integrada por ciudadanos entendidos como base de la vida democrática. Esto supone la defensa de los derechos humanos, del desarrollo 
sustentable, del medio ambiente, de la igualdad de la mujer, la protección de todo tipo de minorías reclamando efectiva realización en las políticas públicas. Asimismo, se realizan balances sobre distintos temas: la izquierda (Aldo Mariátegui), la derecha (Antonio Zapata), la violencia política (Agüero), la historia (Manuel Burga), los partidos y el Estado (Lynch), los intelectuales (Gonzales Alvarado), y la ciencia política cobraría importancia (Eduardo Dargent, Tanaka, Carlos Meléndez, Alberto Vergara). El tema de las relaciones de poder no ocupa un lugar central en los debates pero sí lo hace la discusión sobre el régimen político: democracia o autoritarismo. La cuestión nacional ya no es uno de los problemas principales en los debates. El ideólogo ha perdido espacios y priman los "líderes de opinión".

\section{7}

En las páginas anteriores se ha podido conocer algunos tipos de intelectuales y de manera muy somera sus contextos y debates. Como ha señalado Edgar Montiel (2018), los sujetos de ideas han dejado su huella contribuyendo a dar forma a cierta imagen, sea de manera crítica o aquiescente, de la nacionalidad; sea a partir de las élites o tomando la palabra en nombre del pueblo; a partir del Estado o de la sociedad civil; ingresando a la actividad política o queriendo actuar como la expresión de valores cívicos; sea desde esferas donde se toman decisiones políticas o distante de ellas. Los sujetos de ideas no solo se han dedicado a registrar el estado de las cosas, también han inspirado caminos a tomar colectivamente y han invitado a asumir posiciones concretas; asimismo, han elaborado genealogías y construido narraciones que se han enfrentado entre sí, aunque con la deuda de no haber producido una lectura "universal" para todos los peruanos.

Desde la fundación de la república hace 200 años hasta la actualidad, la nación peruana ha ido ampliando sus contornos y enriqueciendo su contenido, en ese trayecto ha podido alcanzar nuevos grados de democratización. En ese camino avanza, tratando de fundamentar y justificar nuestra pertenencia a una misma colectividad, pues como ciudadanos debemos tolerar nuestras diferencias. Tolerancia es algo distinto a indiferencia. La indiferencia significa no intervenir en lo que haga o deje de hacer el otro con tal que no nos invada o perturbe; tolerancia es, como propone Pietro Barcellona, dar valor al otro en su diferencia y por lo que es $y$, aun así, brindarle un lugar en nuestra propia mesa. La nación — nuestra comunidad imaginada— debería ser construida sobre esta base moral. 


\section{Bibliografía}

AdRIANZÉN, A. (editor) (1990). Pensamiento político peruano. 1930-1968. Lima: Desco.

AdrianZÉn, A. (1987). Pensamiento político peruano, 1900-1930. Lima: Desco.

ANDERSON, B. (1993). Comunidades imaginadas. Reflexiones sobre el origen y la difusión del nacionalismo. México DF: Fondo de Cultura Económica.

ARON, Raymond (s/f). El opio de los intelectuales. Buenos Aires: Ediciones Leviatán.

BASADRE, J. (1978). Perú: problema y posibilidad [1931]. Segunda edición. Reproducción facsimilar de la primera edición de 1931; con el apéndice: "Algunas reconsideraciones cuarentisiete años después", y prólogo de Jorge Puccinelli. Lima: Banco Internacional del Perú.

BoBBiO, N. (1998). La duda y la elección. Intelectuales y poder en la sociedad contemporánea. Barcelona: Paidós.

BouRdiEU, P. (2001). Intelectuales, política y poder. Buenos Aires: Eudeba.

COSER, Lewis A. (1966). Hombres de ideas. El punto de vista de un sociólogo. México DF: Fondo de Cultura Económica.

DENEGRI, F. (2004). El abanico y la cigarrera. La primera generación de mujeres ilustradas en el Perú. Lima: Instituto de Estudios Peruanos.

FLoRES, A. (1980). La agonía de Mariátegui. La polémica con la Komintern. Lima: Desco.

GARAVITO, H. (1986). El santo hereje. Lima: El Virrey.

GONZALES, O. (1994). Sanchos fracasados. Los arielistas y el pensamiento político peruano. Lima: Ediciones Preal.

GonZALES, O. (1999). Señales sin respuesta. Los Zorros y el pensamiento socialista en Perú. 19681989. Lima: Ediciones Preal.

GONZALES, O. (2005). El gobierno de Guillermo E. Billinghurst 1912-1914. Los orígenes del populismo en el Perú. Lima: Nuevo Mundo.

GONZALES, O. (2016). El rol de los intelectuales en la construcción de la nación peruana. Lima: Fondo Editorial del Centro de Altos Estudios Nacionales.

GouldnER, A.. (1980). El futuro de los intelectuales y el ascenso de la Nueva Clase. Madrid: Alianza Editorial.

KONRAD, G. y SZELÉNYI, Iván (1981). Los intelectuales y el poder. Barcelona: Ediciones Península.

KRISTAL , E. (1991). Una visión urbana de los Andes. Génesis y desarrollo del indigenismo en el Perú 1848-1930. Lima: Instituto de Apoyo Agrario.

LANDÁZURI, J. (editor) (2015). Los inicios. Lima: Fundación Armando Villanueva.

LöWY, M., (1978). Para una sociología de los intelectuales revolucionarios. La evolución política de Lukács, 1909-1929. México: Siglo XXI. 
MARTíN, J. (2002). La revolución peruana: ideología y práctica política de un gobierno militar, 1968-1975. Sevilla.

MALDONADO, T. (1998). ¿Quées un intelectual? Aventuras y desventuras de un rol. Barcelona: Paidós. MoLINARI, T. (2009). El fascismo en el Perú. La Unión Revolucionaria 1931-1936. Lima:Universidad Nacional Mayor de San Marcos-Facultad de Ciencias Sociales.

MolinARI, T. (2017). Dictadura, cultura autoritaria y conflicto político en el Perú (1936-1939). Lima: Universidad Nacional Mayor de San Marcos-Facultad de Ciencias Sociales.

MonTIEL, E. (2010). El Inca Garcilaso y la independencia de las Américas. Cuadernos Americanos. 131:1.

MontIEL, E. (2018). Ensayos de América. Interrogar nuestro tiempo. Compilación de Joel Rojas. Lima: Universidad Nacional Mayor de San Marcos.

PLANAS, P. (1994). La república autocrática. Lima: Fundación Friedrich Ebert.

REY DE, A.(2008). El pensamiento político y la formación de la nacionalidad peruana, 17801820. Lima: Universidad Nacional Mayor de San Marcos-Facultad de Ciencias Sociales.

SANDERS, K. (1997). Nación y tradición. Cinco discursos en torno a la nación peruana, 1885-1930. Lima: Fondo de Cultura Económica.

VARGAS, M. (1993). El pez en el agua. España: Alfaguara.

VARILLAS, A. (2008). El periodismo en la historia del Perú. Desde sus orígenes hasta 1850. Lima: Universidad San Martín de Porres-Fondo Editorial.

Weber, M. (1988). El político y el científico. Madrid: Alianza Editorial.

ZNANIECKI, F. (1944). El papel social del intelectual. México DF: Fondo de Cultura Económica. 